\title{
Biocultural stewardship, Indigenous and local ecological knowledge, and the urban crucible
}

\author{
$\underline{\text { Heather L. McMillen }}^{1}, \underline{\text { Lindsay K. Campbell }}^{2}$, Erika S. Svendsen $^{2}, \underline{\text { Kekuhi Kealiikanakaoleohaililani }}^{3}, \underline{\text { Kainana S. Francisco }}^{4}$ \\ and Christian P. Giardina ${ }^{4}$
}

\begin{abstract}
Although biocultural stewardship models have been written about widely, especially in Indigenous and rural communities, the practice of applying them in multicultural, urban environments has rarely been explored. We have yet to realize the full potential of kinship-linked, place-based stewardship models in highly diverse and densely populated urban settings. Here we explore how the concept of biocultural stewardship can be applied to a cosmopolitan, urban setting. To do this, we draw upon our experiences as participants and leaders in collaborative projects in New York and Hawai i to consider how diverse knowledge systems and colearning engagements can strengthen a community of practice and enrich our stewardship efforts. Our collaborative projects include stewardship trainings based in a Native Hawaiian perspective (Hālau 'Ōhi'a) that were adapted for New York City stewardship practitioners (Learning from Place) and subsequently inspired the creation of a New York City-based community of practice (Stewardship Salons). We identify various meanings in diverse practices of stewardship and the ways in which these concepts travel across different geographical contexts and culturally distinct communities. We stress that the meanings and practices resulting from such an integration are important because they shape the conceptualization of resources, their management, and the rights and responsibilities people have for stewardship of their places. We conclude that a biocultural approach to stewardship can help reorient stewardship practices in any context, including urban ones. A shift toward biocultural stewardship can have many positive effects for urban environmental stewardship, but also for much broader applications related to cultivating sustainability and well-being on a planet undergoing rapid environmental, social, and climate change.
\end{abstract}

Key Words: biocultural stewardship; civic environmentalism; Hawai $i$; Indigenous and local ecological knowledge; New York City; urban

\section{INTRODUCTION}

Merriam-Webster defines "crucible" as a "place or situation in which concentrated forces interact to cause or influence change or development." In this regard, urban environments are very much places where forces are concentrated, forming centers that cause or influence change. In considering the crucible as a "vessel of a very refractory material used for melting and calcining a substance that requires a high degree of heat," the word becomes an apt metaphor for the urban landscape as an enduring physical vessel where over time and under intense social pressure, different groups interact to create something novel. For these reasons, we use the crucible as a metaphor for describing urban biocultural stewardship.

Resource stewardship has roots in a diversity of ancient practices, often founded on intimate connections between humans and nature. In some communities, human-nature relationships have long been and continue to be enshrined within a concept of kinship, and codified in cultural practices founded on the intergenerational accumulation of knowledge about the socialecological system that sustains them (Berkes 2012, Pascua et al. 2017, McMillen et al. 2017). The kinship quality of resource relationships is not unique to rural Indigenous communities of the past, but rather continues to define resource relationships for contemporary Indigenous and other local communities, and can be seen as broadly defining people's relationships to nature across time (Nash 2014), including in urban areas (Elands et al. 2019). In urban centers, stewardship has been practiced in the pursuit of cultivating resources that sustain body, mind, and spirit
(Barthel et al. 2005, Colding et al. 2006, Svendsen et al. 2016a), and these practices have evolved in response to ever changing social-ecological urban systems. Stewardship has long been a key feature of resilience thinking, especially in relation to ecosystems and the biosphere (e.g., Berkes et al. 1998, Chapin et al. 2009, Folke et al. 2016), and more recently specifically in urban areas (Andersson et al. 2014). Today, the promise of community-based stewardship of place is increasingly recognized as critical to the sustainability of our planet (Tengö et al. 2014), including the following: our capacity to respond to global environmental change (Olsson et al. 2004, Enqvist 2017); support biocultural diversity (Muhumza and Balkwill 2013, Elands et al. 2015) and human well-being (Svendsen et al. 2016a); promote socialecological resilience (McMillen et al. 2016, Kealiikanakaoleohaililani et al. 2018, 2019, Dacks et al. 2019); and sustain identity, values, responsibilities, and social relationships (Chan et al. 2016a). In this article, we explore urban centers as crucibles where intense forces drive the mixing of biocultural elements; we do so with the hope that this article can catalyze the creation of new models that enhance the well-being and resilience of urban social-ecological systems.

Migration is a common pattern across human history and across the planet (Manning 2013). An important driver of migration that continues to the present is the search for new areas rich in resources and favorable living conditions. Today, residents of rural communities increasingly migrate to urban centers in search of employment, freedom, and improved living conditions, bringing with them local and Indigenous knowledge about the

${ }^{1}$ Hawai'i Department of Land \& Natural Resources, Division of Forestry \& Wildlife, Kaulunani Urban \& Community Forestry Program, Honolulu, HI, USA, ${ }^{2}$ USDA Forest Service, Northern Research Station, NYC Urban Field Station, Bayside, NY, USA, ${ }^{3}$ Hālau 'Ōhi'a - Hawai i Stewardship Training, Hilo, HI, USA, ${ }^{4}$ USDA Forest Service, Pacific Southwest Research Station, Institute of Pacific Islands Forestry, Hilo, HI, USA 
social-ecological systems of their previous homes (Shava et al. 2010, Nesheim et al. 2006). Regardless of whether urban centers are close to or distant from rural areas of origin, new urban residents and their descendants often apply and adapt their knowledge from their previous home to steward their new urban environment (Cocks and Dold 2006, Chan et al. 2016b). As a result, a ubiquitous feature of contemporary urban life is the assembly of diverse multigenerational stewardship approaches operating not just in close proximity, but often in overlapping fashion on common resources. This juxtaposition creates the context for the "urban crucible" where various biocultural, Indigenous, and local knowledge systems interact. Although this can create conflict, tensions can also drive surprising integration, adaptation, and the creation of something highly innovative.

It is within this crucible that urban stewardship has and continues to evolve. Urban stewardship then, can be seen as a hybrid expression of care for community and place, but care that is grounded in imported social norms, practices, and spiritual beliefs that have been adapted to the new urban context (Svendsen and Campbell 2008, Svendsen et al. 2016a). The urban crucible also requires that organizational structures in the urban environment shape stewardship (Fisher et al. 2012), much as the laboratory chemist stewards the process of mixing and heating elements to achieve a desired outcome. Along with the comingling of knowledge systems, this process also involves the collaborative production of new knowledge (Tengö et al. 2014), and ideally the collaborative, but at least cooperative, participation of people with often very different cultural backgrounds. At the same time, the multiple challenges of sustainability in a time of accelerating global environmental change can encourage communities to seek out other ways of knowing and being, as ways to care for the people and places in their communities. Specifically, the urban social-ecological system requires that multiple and necessarily diverse knowledge systems interact in the process of creating and applying novel ideas and practices to the stewardship of urban resources, and in the process the knowledge systems shape and become shaped by these resources.

To illustrate this process more concretely, this article explores how a Native Hawaiian epistemological process and worldview was adapted and applied in New York City (NYC) to elicit a conversation about and support processes of biocultural stewardship. We also consider what this exchange has meant to stewards of the complex urban context that is NYC. This powerful and transformative cross-cultural exchange, (1) began with Native Hawaiian stewardship trainings held in Hawai'i (Hālau'ōhi' ${ }^{a}$ ); (2) was adapted for NYC stewardship practitioners ("Learning from Place"); and (3) subsequently inspired the creation of a NYCbased community of practice ("Stewardship Salons"). This very intentional bringing together and mingling of biocultural knowledge systems in NYC allowed participants to share their unique cultural and geographical experiences, identify and explore commonalities, and begin fusing elements into a dynamic growth process for enhancing the creation of a new urban stewardship ethic. Here we report on this innovative process and share specific examples from participants on its broader applicability.

To do this, we (the coauthors) drew upon our experiences as participants and leaders in stewardship projects, workshops, and trainings in NYC and Hawai $i$ to consider how diverse knowledge systems and colearning practices can strengthen community and place-based stewardship. We found that the integration of meaning and practice resulting from such exchanges enabled practitioners to reconceptualize the nature of resources, the relationship between steward and resource, and the goals of resource stewardship. From this exchange-driven process, participants were also able to elaborate the rights and responsibilities associated with place-based stewardship.

To advance our understanding of how apparently disparate knowledge systems can be integrated in an urban context to advance stewardship objectives, we review Indigenous and placebased stewardship and urban civic environmentalism and stewardship, which represent two distinct stewardship models that contrast strongly with respect to academic and geographic lineages but as we found during our exchanges, also have overlapping elements. When developing biocultural approaches to stewardship, it is important to view cultural resources as equal to natural resources, and to conceptualize stewardship not simply as the care of resources, but rather a system of practices that focuses on caring for the larger network of relationships defining the social-ecological system. Biocultural stewardship defined this way recognizes critical feedbacks between ecological and human well-being (Gavin et al. 2015), whereby stewardship of place is inseparable from stewardship of people, their cultural practices, and their values (Pascua et al. 2017). We see biocultural stewardship then as engaging not only individual plants and animals, species and lifeforms, habitats and niches, landscapes and seascapes, but also the spiritual, emotional, and psychological well-being of community and family members, which includes the human and nonhuman (Donatuto et al. 2014, Svendsen et al. 2016a). Our approach aligns with a growing body of work that situates the biocultural paradigm as powerful for contributing to local and global sustainability (Merçon et al. 2019) and understandings of resilience (Dacks et al. 2019).

\section{Indigenous and place-based stewardship}

Biocultural stewardship includes but is not restricted to Indigenous and place-based stewardship and so is aligned with Indigenous and local ecological knowledge systems (Turner et al. 2000, Berkes 2012). In some knowledge-practice-belief systems, nonhuman elements of nature, i.e., stones, minerals, plants, animals, soil, geographic features, elements of weather, etc., are often understood to be animate, sentient beings with agency (Watts 2013). Some societies have no concept of "nature" or "culture" and people are defined by transactive interactions with their environment (Gillison 1980, West 2005). Many Indigenous epistemologies define family as extending beyond the human species to include all living and nonliving components of a system, what has been described as kincentric ecology by Salmón (2000) who illustrates the concept with examples from his Rarámuri culture of the Sierra Madres in Mexico. In some cultures, humans are often depicted as a child or younger sibling (Johnson et al. 2016). For example, in Hawai i reciprocal relationships of people and place are embodied in the concepts 'àina as 'ohana (land as family) and keiki o ka 'āina (child of the land), which are held as grounding philosophies of life (McGregor 2007, McMillen et al. 2017). In Hawai' $i$ the process of observing and monitoring ecosystems is a way to maintain or restore familial relationships 
to place, and to strive for 'àina momona (lit. rich, fertile land; Morishige et al. 2018). Winthrop (2014) uses the term "culturally reflexive stewardship" to describe the ways that Indigenous communities of the Pacific Northwest (USA) demonstrate familial commitment to their landscapes. Similarly, other Indigenous scholars from the Pacific Northwest and the Great Lakes regions (North America) describe stewardship as community based and intergenerational guardianship that is sustained through reciprocal exchange (Johnson et al. 2016, Whyte et al. 2016). Whyte et al. (2016:29) explains that "Humans are stewards or caretakers not because they are privileged as knowledge holders, but more because they are in the position of having responsibilities to the many other relatives making up the genealogical community."

Central to our understanding of biocultural stewardship then is the principle that resulting kinship networks drive perceptions of resource as family that are distinct from market driven perceptions of resource as commodity (Kealiikanakaoleohaililani and Giardina 2016, Pascua et al. 2017). Tipa and Teirney's (2006) Cultural Health Index highlights the interconnections between the health of people and place. They identify cultural factors that impact Māori well-being, including links between lands and genealogy, exercise of customary custodianship, ancestral teachings, life giving forces, and kinship. These worldviews are enshrined in cosmologies that structure and reinforce an understanding of reciprocal caring relationships between people and place, relationships that place humans as guardians of nonhuman family members (Johnson 2013).

Rights and responsibilities are often central considerations within Indigenous resource stewardship systems. For example, the sustainable development model of the College of Menominee Nation in Wisconsin, USA, incorporates land and sovereignty; natural environment (including human beings); institutions; technology; economy; and human perception, activity, and behavior (Dockry et al. 2016). Further, defining features of biocultural stewardship (Caston 2013) have come to include cultural self-determination (e.g., self-definition of the group and its decision-making process), blended knowledge (e.g., spiritual understanding of nature, a holistic way of promoting conservation and sustainable use), and political engagement (e.g., call for respect for the group's own laws and protocols, as well as their national and international rights). Watts (2013:22-23) explains that the importance of rights to nature and land for Indigenous people are directly linked to their responsibilities to steward it: "if we do not care for the land we run the risk of losing who we are as Indigenous peoples ... It is not only the threat of a lost identity or physical displacement that is risked but our ability to think, act, and govern becomes compromised because this relationship is continuously corrupted with foreign impositions of how agency is organized." We therefore view rights and responsibilities as being paired concepts in a dialectical relationship. Clearly, there can be an emphasis on one over the other, and balance can vary temporally and spatially. The dynamic between these concepts is also a theme in other frameworks for stewardship, including civic environmentalism.

\section{Civic environmentalism and stewardship in urban contexts}

Civic environmentalism has evolved over time, especially in urban social-ecological systems. In the United States, the civic environmentalism of the post-1970s era tended to take the form of social movements that engaged issues of conservation, civil rights, antitoxics, and social justice (e.g., Bullard 1990, Brulle 2000, Mertig et al. 2001). More recently, civic environmentalism has incorporated elements of education, self-help, and building community capacity to contribute to the environmental restoration and sustainability of communities through participation in collaborative, locally based resource management (e.g., Burch and Grove 1993, Westphal 1993, Shutkin 2000, Sirianni 2006). As a result, civic environmentalism in both urban and rural areas can be expressed through community stewardship by groups that are proactively managing sections of the landscape and planning for its sustainability, including areas that have been affected by hurricanes, terrorist attacks, depressed economies, structural racism, and war (Dalton 2001, Agyeman and Angus 2003, Krasny and Tidball 2015).

We define civic environmental stewardship as the practice of conserving, managing, monitoring, transforming, educating about, and advocating for a wide range of quality of life issues (Svendsen and Campbell 2008, Fisher et al. 2012; Campbell et al. in press). Through research with origins in New York City, but methodologies that have been broadly applied across a dozen different regions in the United States and globally (e.g., Romolini et al. 2013, Muñoz-Erickson et al. 2017, Blanc and Paddeu 2018), we have found that civic environmental stewardship is pursued by environmental groups, e.g., park conservancy groups, community garden groups, or harbor estuary groups, but also other civic groups that take on environmental issues, for example neighborhood associations that do tree plantings and maintenance, or youth groups that conduct neighborhood park clean-ups (Svendsen et al. 2016b). Many urban civic groups have missions that span different domains of environmental protection and community development; these may be place-based or issuebased (Connolly et al. 2014, Enqvist 2017). Stewardship can both improve social-ecological functioning (Connolly et al. 2013) and can serve as a catalyst for broader and deeper civic engagement (Fisher et al. 2015, Yagatich et al. 2018).

Local groups such as neighborhood associations, faith-based and culture-based communities, recreational clubs, and civic clubs have multiple motivations for practicing stewardship, including securing resources, improving landscape aesthetics, and supporting place-making and local identity (Bennett et al. 2018, Sonti and Svendsen 2018, Enqvist et al. 2019). For instance, Andersson et al. (2014:449) explain "in collectively managed gardens, community engagement results in a shared history manifested in artifacts, locally adapted organisms, trees, landscape features, and written accounts (Nazarea 2006; Barthel et al. 2010). These objects tend to outlive the practices that first shaped them and function as shared memory carriers between people and across generations (Barthel et al. 2010)." Clearly, biocultural relationships are not specific to rural or Indigenous communities, nor relegated to the past, but rather continue to define resource relationships for a wide diversity of contemporary communities and can be seen as broadly defining people's relationships to nature (Nash 2014), including in urban areas (Cocks et al. 2016, Elands et al. 2019). 


\section{Biocultural stewardship as a framework for urban and global communities}

Place-based biocultural practices often are driven by values, norms, and beliefs aligned with being sustained by nature while caring for and being in relationship with nature (Chan et al. 2018). The resulting knowledge systems and associated practices extend into and persist in urban areas (Cocks and Weirsum 2014, Elands et al. 2015, Merçon et al. 2019). A core assumption here is that biocultural stewardship as a practice is intensely place based, but not place bound. Implicit then are the ideas that (1) biocultural stewardship practices contain highly site-specific elements and universal elements that allow stewards to find common ground with other stewards across geographies; and (2) finding common ground may require that stewards be willing to engage different values, norms, beliefs, and ways of knowing, and in some cases re-evaluate or even deconstruct their own knowledge system. Although biocultural stewardship models have been widely described (e.g., Berkes 2012), the practice of integrating placebased models of stewardship into multicultural urban environments has rarely been explored (Buizer et al. 2016). And although biocultural diversity has been articulated as a goal for managing urban green space (Buizer et al. 2016), the realized and potential benefits of applying kinship-linked, place-based biocultural stewardship models in cosmopolitan and densely populated urban settings has rarely been described.

We posit that embracing biocultural stewardship enhances psycho-social-spiritual well-being for urban dwellers (Svendsen et al. 2016a), while helping stewards to cultivate sustainability on an increasingly urbanized planet undergoing rapid environmental, social, and climate changes (Sterling et al. 2017). By engaging multiple, varied, place-based relationships with the natural world (Krasny and Tidball 2015), biocultural stewardship can catalyze efforts to develop more effective approaches to thriving in a dynamic environment. We have much to learn from place-based, kincentric models of resource stewardship as they offer a pathway to social-ecological resilience and community well-being that may not be achievable under approaches that are purely agency based, and severely funding constrained (Svendsen et al. 2016a, Kealiikanakaoleohaililani et al. 2018).

\section{METHODS}

Drawing upon our experiences as participants in biocultural stewardship efforts, we presented our learning during an exchange (2016-2018) between stewards from the islands of Hawai'i and NYC through both Hālau 'Ōhi' $a$ and Learning from Place, subsequent analyses of discussions, and a series of Stewardship Salons in NYC. In this sharing, we have incorporated our personal reflections, field observations, and debriefing notes as well as quotations from participants' reflections in program evaluations. This larger collection of exchanges represents a type of colearning that can cultivate bioculturally rooted approaches to resource stewardship, and we seek to illustrate how our exchange developed in two socioculturally, ecologically, and epistemologically complex, yet geographically distinct areas. Our exchange was structured to facilitate discussion of theory and practice, but also included group storytelling, ritual, and artistic performance to engage other elements of the human experience. Such coproduction of "useable knowledge" has become a popular approach in sustainability science communities, and the knowledge system framework has been shown to be useful in revealing the types of societal relationships (e.g., MuñozErickson et al. 2017, Fernández-Llamazares and Cabeza 2018).

\section{RESULTS}

\section{Developing a biocultural stewardship training program: Hālau 'Ōhi' a, Learning from Place, and New York City Stewardship Salons}

\section{Hālau 'Ōhi'a}

Hālau 'Ōhi'a is the creation of Kekuhi Kealiikanakaoleohaililani, a Кити or master teacher whose family is from Hawai $i$ and who has been practicing Hawaiian hula (dance), chant, and ritual for over 40 years. Her breadth of knowledge and experience is a continuation of her ancestors' practices and creations. A hālau (lit. "many breaths") is a place of learning; 'ōhi a (lit. "to gather") is ecologically and culturally the most important native tree species in Hawai'i (Metrosideros polymorpha Gaudich, Myrtaceae). Hālau 'Ōhi' $a$ then is an intensive professional and personal development training program in Hawai i lifeways, of which stewardship is an embedded element, for developing the capacity of conservation and natural resource professionals in Hawai $i$. Its multidimensional framework allows professionals to engage self, others, and place (Kealiikanakaoleohaililani et al. 2018, 2019) through Native Hawaiian rituals, telling of sacred stories, performing traditional chants and dance, and creating poetic texts and art forms.

By engaging in these practices and in relationships with surrounding land and seascapes, learners are able to cultivate multiple ways of knowing their biology, minds, and spirits while establishing or deepening kincentric relationships with their communities and their places. Hâlau 'Ohi' a trains learners in a set of specific skills based in Hawai'i lifeways and ritual that can be used in professional resource management settings (see Kealiikanakaoleohaililani et al. 2018, 2019 for details). The ultimate goal of this learning is "no less than to transform the way we view and steward our lands and seas" (Kealiikanakaoleohaililani et al. 2018:3478). There were 24 learners in the first cohort (initiated in 2016 with 75 learners), 35 additional learners in a second cohort (initiated in 2018 with 65 learners), with both cohorts gathering in Hilo on Hawai i Island. A third cohort of about 100 learners was initiated in the city of Honolulu on O'ahu at the end of 2018, and a fourth cohort of 45 learners was initiated on O'ahu in July of 2019 at the time of this writing.

The first skill that is taught is the mele komo. A mele is a Hawaiian poetic text. A mele komo is recited as a chant in a ritual that requests permission to enter, as part of the preparation for entering into a space by opening ourselves to learning. Each class begins with the mele komo and is followed by the ritual of collaboratively creating the kuahu (altar, typically adorned with plants) as a portal to entering into sacred space. To embody the knowledge that we are all in kinship relationships with the living and nonliving components of the social-ecological system, mo'oku'auhau (genealogical chant) is another skill that is taught. Mo'o translates to continuum and so the mo'oku' auhau conveys our interconnections over generations and across space. The creation and recitation of one's mo'okū'auhau includes the people 
who raised us as well as the mountains and water sources that sustain us. A third skill learners practice is to engage and interpret ka'ao (sacred texts and mythological creation stories, hereafter stories). Reading, listening to, and telling these stories is a valuable practice because tapping into their dynamic teachings can enhance our understanding of place and of relationships to place (see Fernández-Llamazares and Cabeza 2018). To delve into the stories, Kekuhi teaches learners to use the multilayered framework of the $k i i i$, which literally means "reflection." This learning process is structured around recognizing and learning from three levels of $k i i$ within every story: Ki $i$ A $\mathrm{A} k e a$ (meta- or universal images); Ki i Honua (macro- or regional images); and, $K i$ i ' Iaka (micro- or personal images). These elements help us to interpret and connect to stories at global, regional, and personal levels (Kealiikanakaoleohaililani et al. 2018, 2019). They also help us find both the intensely personal but also the universal in the materials we engage, a particularly important concept with respect to our Learning from Place and Stewardship Salon processes.

Through exchanges among the authors, we saw an opportunity for colleagues from Hawai i $\mathrm{i}$ and NYC to learn together. We realized that we have a collective need to share stories, exchange experiences, and learn from the people, places, and practices that occur across our communities. We recognized the need for a shared space to engage in conversations about what we do, to collaboratively create new stories, artwork, curriculum, programs, and articles, and to be inspired to bring new ideas back into our workplaces. We recognized the potential challenges that can come from the enormous geographic and cultural diversity among participants; however, we also saw the potential for those differences to help us meet our shared desire for meaning, purpose, and connection.

\section{Learning from Place}

In October 2017, we organized Learning from Place, a two-day exchange led by Kekuhi and relying on Hālau 'Ōhi' $a$ approaches, exercises, and concepts (described above) adapted for the context of NYC. Our aims were to catalyze colearning about connecting to place and cultivating stewardship across regional, professional, cultural, and personal levels; identify and understand NYC cultures as they relate to stewardship of the urban environment; and develop a framework for a stewardship training program for NYC that can be piloted and further developed with local groups. We assembled a group that may be best described as the "stewards of NYC stewardship," including 45 stewardship practitioners, land managers, educators, artists, and researchers based in NYC (including E.S. and L.C.); three Hālau 'Ōhi' $a$ participants from Hawaici (including KSF and C.P.G); one participant who was associated with both NYC and Hālau 'Ōhi' $a$ (HM); and Kekuhi (KK).

The workshop began in Bushwick Inlet Park, a waterfront park, in the NYC Borough of Brooklyn (Fig. 1); with Kekuhi leading participants in a mele komo with the chanted ritual of asking permission to enter the physical space and to be open to engaging in the experience. Two representatives of NYC (HM, through her professional affiliation, and CG through his familial connection) responded with a mele $k$ āhea, a response chant warmly welcoming all the participants inside. After everyone was seated, Kekuhi led a discussion about the ritual and its function. At the end of the second day, participants created their own mele as a way of engaging and learning from place. Here, we include anonymous, voluntary, reflections shared by NYC participants after the workshop as part of an internal program evaluation. Their quotes illustrate applications of the mele komo to a broad setting beyond Hawai'i. Themes of respect, gratitude, and intentionality resonated among participants who easily made connections to their own work settings and the communities they engage. One person shared:

Fig. 1. Learning from Place workshop participants explore Bushwick Inlet Park for inspiration to create origin stories.

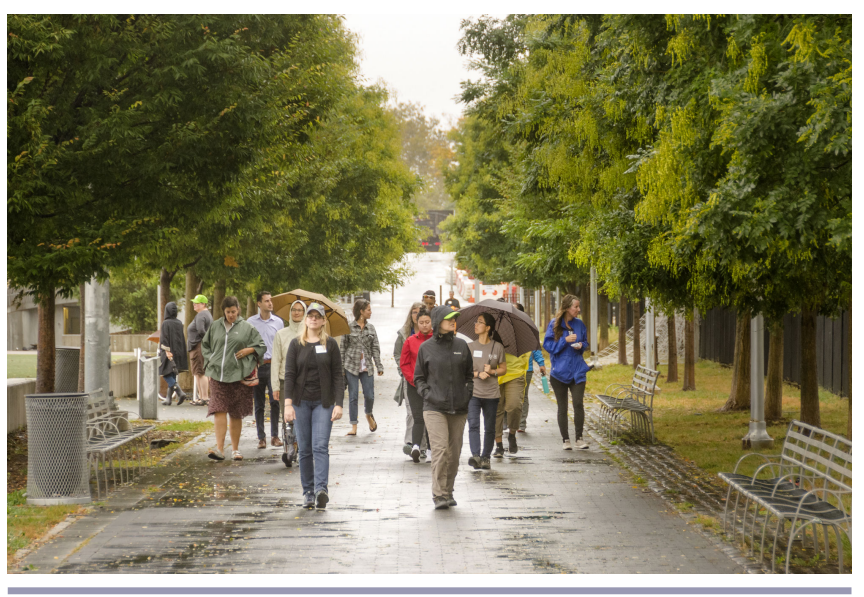

I like that this ritual [mele komo] makes you think about being respectful when entering a new (physical or cultural) space or space that doesn't belong entirely to us. I like that it forces us to think through our intentions before engaging, and I feel that this way of thinking is really important for outreach efforts to communities that historically haven't been approached by environmental stewardship groups before.

Another explained:

The Mele Komo was a great opportunity to reflect on how gratitude can and should be expressed for being allowed to share space with people, animals and plant people. It's easy to forget or to feel entitled to access to things, people and place but the Mele Komo teaches reverence, respect and humility for being where we are and how to reciprocate after receiving the gift of entry. This one really resonated.

Participants learned from Kekuhi and her Hālau 'Ōhi'a model (Fig. 2), and from each other by looking at their relationships to people and place through the three-tiered $K^{i} i$ framework. We deepened our understanding of these relationships through the lens of stories. We listened to and observed Kekuhi share the ka'ao of Papa and Wākea (one of the stories of Earth Mother and Sky Father who birthed the Hawaiian Islands, the taro plant, and the Hawaiian people) and in small groups we explored the origin stories of other people and places (Fig. 3). We then created, drew, and performed our own creation stories and poetic texts inspired by the places, plants, and people that surrounded us during the exchange, but also that we carry with us as part of our being (Fig. 
4). Several participants quickly understood the power of katao and made connections to how it can be applied in their own work to heighten connections among people and place and to identify opportunities for communities to connect to and share with each other. Here are reflections from four participants:

Fig. 2. Kumu Kekuhi describes the $K i i$ framework.

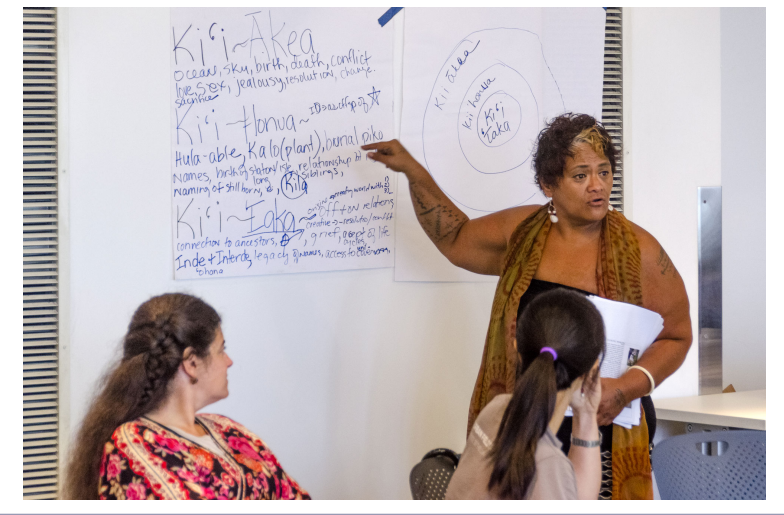

Fig. 3. Small groups of Learning from Place workshop participants discuss origin stories.

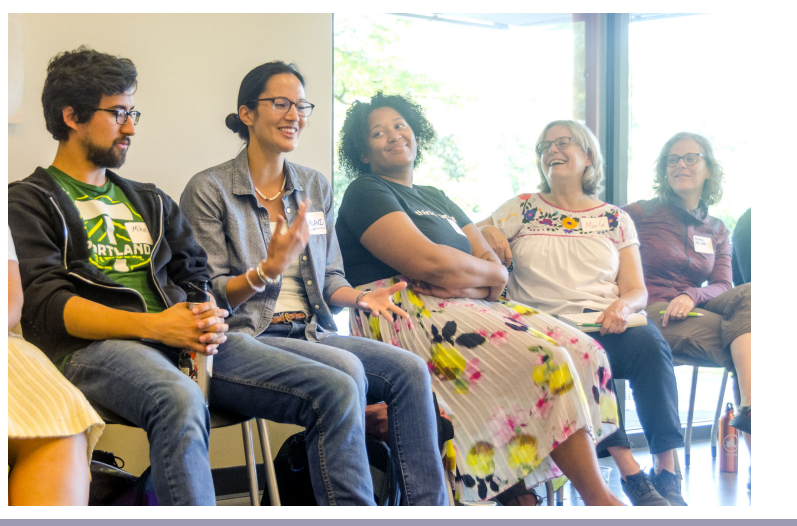

Fig. 4. Learning from Place workshop participants perform their collaboratively created origin stories.

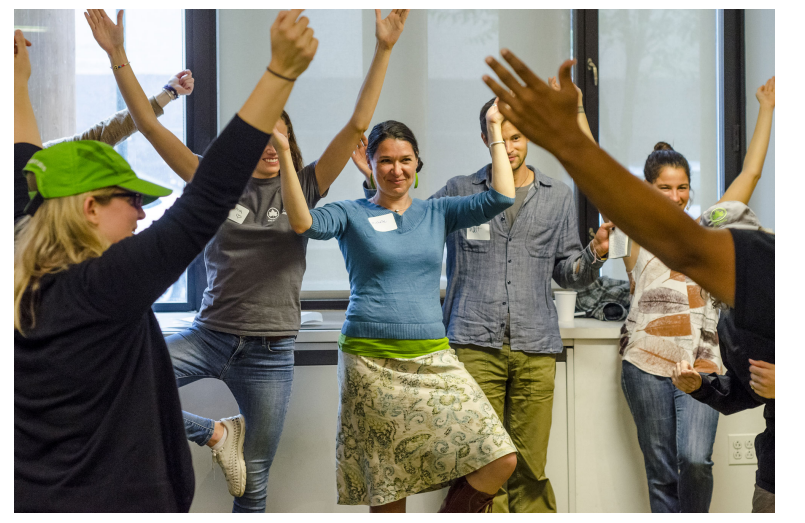

I found the storytelling and story/myth interpretation process to be an interesting way to learn about fellow participants and their perspectives. By all analyzing a myth together, using the different lenses, we were able to connect with one another in a way that probably wouldn't have happened otherwise, as people shared elements of their own lives and experiences.

Definitely resonated! So much of my job focuses on helping technical specialists find ways to communicate their data and methods with the general public. The storytelling piece of the workshop gave me a lot of food for thought about how to do this more effectively.

Really enjoyed hearing all of the origin stories folks shared. If I was working with a group or students continuously, I can see this as an engaging activity for students to connect to their neighborhood and create their own origin story. Or I can see a community garden rallying together and creating a story for their space.

I was so excited that this was a part of the conference. The idea that most of us anchor ourselves (at least the folks in that room) in either a landscape or a memory of landscape was a powerful reminder of the power of place and importance of landscape. I need to try and incorporate this as an icebreaker in future classes and walks I might give.

On the second day, we met at Queens Botanical Garden in the NYC Borough of Queens. There, we experienced embodied knowledge through hula (dance), hei (string images that illustrate songs and stories; Fig. 5), and the cocreation of a kuahu adorned with meaningful plants and other living things chosen by participants, and which served as a portal to creating a sacred space for dialogue and learning. Two participants shared about the kuahu experience:

Fig. 5. Kukmu Kekuhi and Hālau 'Ōhi' $a$ learners from Hilo, Hawai'i demonstrate the hei (string images that illustrate songs and stories) for the mele (song) Kānehoalani from the story of Pele and Hitiaka.

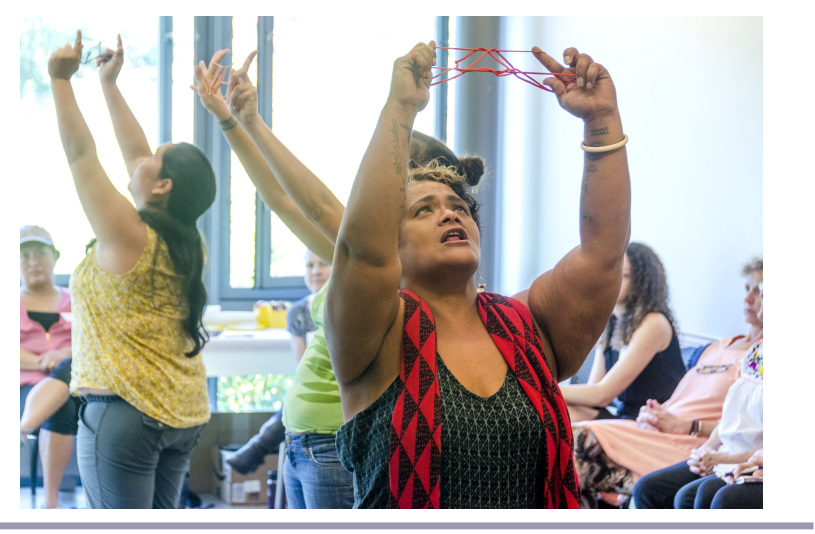

Created a sense of shared space for me, with other workshop participants. I kinda wish we had done this first as I think it may have been a useful way for us to become a group more quickly - I realize that wasn't the point of the workshop, though. 


\begin{abstract}
I would love to be able to wrap this into one of our monthly team meetings, just trying to figure out a way to sell the idea to my supervisor. I think the altar is a great way to share with the team what you want to get out of the session and for everyone to think creatively.
\end{abstract}

As mentioned above, the nested $K i$ i $i$ framework was used throughout the workshop as a framework and this also seemed to resonate strongly with participants who wrote about how they internalized it and imagined using it in their own work. Here are quotes from three participants:

\begin{abstract}
The framing of the kit is took time to understand but I think the exercise of grappling with the meaning of each ki $i$ help [ed] us to work together using a common language. I think using that frame throughout the workshop also helped us all remain grounded by its principles and help [ed] us open up by being introspective, vulnerable within the communal space and enthusiastic about expanding our understanding of how ki $i$ is applied at different scales.
\end{abstract}

This was also highly resonant, specifically because it aligns very closely with [specific group's] approach to building interpretive programs by explicitly building universal themes into programs.

This seems like an incredible tool for relating to almost any kind of literature. And I like how it pushes us to think very globally and very locally. Right now I'm not working with literature in much depth, but if that comes up in my work, I would consider using these approaches. I don't see myself referencing Hawaiian culture or language, since I know nothing about that. But I do see myself taking inspiration from the concentric circles, and using my own language and culture to express my understanding of those categories.

The $K i{ }^{i} i$ framework resonated with the practitioners assembled as many struggle to work across space and scale in NYC. In earlier conversations, participants shared that often the tasks of engaging New Yorkers in nature is challenging just based upon the sheer number of residents as well as the skepticism that can exist around the qualities of urban nature as compared to places that are considered more pristine and "natural." By the end of this session, participants took hold of the pathway that resonated most with them and were intent on applying the $K i{ }_{i} i$ framework to their own work.

\section{Stewardship Salons}

As a result of the exchanges between NYC and Hawai i, NYCbased authors were inspired to create a year-long series of monthly Stewardship Salons. The intent was to establish a community of practice that would encourage participants to share their "stewardship origin stories" to uncover moments of personal transformation and apply this learning to stewardship practice. In a city of almost 9 million, it can be humbling to start. Any table you set is not wide enough, not inclusive enough, and is limited in some way. Kekuhi encouraged us to start with colleagues whom we know and to trust that the people who needed to be there would be there. Starting in June 2017 and meeting monthly for 12 months, a cohort evolved, ranging from 10-25 researchers, land managers, artists, and practitioners, all of whom expressed interest in strengthening connections to place and people as well as challenging themselves with new perspectives.

For our first meeting, we shared our own personal stewardship stories, and set a common sense of purpose, including a set of formal ground rules that we revisited and reaffirmed at the beginning of each of the 12 meetings. These include confidentiality (what was shared by participants during a meeting was not shared outside of that meeting); ideas documented in our note taking were not attributed to anyone except when shared by the featured host speaker; all participants were asked to participate as individuals, not as employees of or supervisors within their organizations; and all participants were asked to remain "all in," which included having electronic devices turned off. We also created a meeting structure that affirmed the ground rules; opened with the request that all share personal stories in response to that month's theme; provided a brief discussion from a featured speaker; supported group discussion in response to guided prompts; and supported casual sharing with an optional time to socialize. This basic scaffolding created a framework that enabled many voices and perspectives to be engaged in a respectful and open manner. We documented key outcomes and insights from this rotating community of teachers and learners, each taking on different topics at different locations (see Table 1).

Across the two-day Learning from Place workshop and the 12 Stewardship Salons, we documented common themes that participants consistently emphasized, engaged, and shared about their sense of place, place attachment, place meanings, and place histories. In discussing a range of place histories, we discussed whose stories were told most often and why, and whose were potentially marginalized or ignored in dominant discourses. We examined stewardship as a form of caretaking, as an embodied practice, as a form of knowledge creation, and as part of a complex knowledge system with a wide range of multilevel drivers and inhibitors. The theme of "many ways of knowing" surfaced often as we shared insights about local ecological knowledge, Indigenous knowledge, embodied knowledge, and practical knowledge from learning-by-doing. We also discussed stewardship ethics, participant's spiritual rituals, practices, and beliefs, and how stewardship can be spiritually grounded including two salons on Judaism and Hinduism. As a group, we explored different ways to create and institute our own rituals as part of the salons, including opening and closing protocols to meetings, seating arrangements in a circle, and always incorporating food and drink. Although these protocols were not grounded in multigenerational cultural traditions as those shared by Kekuhi, they were nonetheless important for establishing our shared community of practice.

To keep continuity between and beyond the monthly meetings and to create a resource repository, we launched a shared web site (closed to people outside the group) where agendas, anonymous notes, and articles were posted, and where comments and other materials continue to be shared. After each salon, our planning group held debrief discussions to reflect on key themes, patterns, and topics that emerged over the course of the Stewardship Salons. Here we learned the value of creating a sort of sacred space where participants were safe to engage deeply personal themes, emotions, perspectives, and practices. Although these spaces clearly exist within religious communities, such "secular 
Table 1. Stewardship Salon dates, hosts, locations, topics, and resources.

\begin{tabular}{|c|c|c|c|c|}
\hline Date & Hosts & Location & Topic and Approach & Related web resources \\
\hline June 2017 & $\begin{array}{l}\text { Lindsay Campbell \& Erika } \\
\text { Svendsen (USDA Forest Service, } \\
\text { USDA FS) }\end{array}$ & $\begin{array}{l}\text { JM Kaplan Fund } \\
\text { Office Midtown, } \\
\text { Manhattan }\end{array}$ & $\begin{array}{l}\text { Shared personal stewardship } \\
\text { stories and objects; created } \\
\text { ground rules and scaffolding } \\
\text { for Stewardship Salons }\end{array}$ & $\begin{array}{l}\text { https://www.nrs.fs.fed.us/nycl; } \\
\underline{\text { https://www.nrs.fs.fed.us/STEW-MAP/ }}\end{array}$ \\
\hline July 2017 & $\begin{array}{l}\text { Sophie Plitt (formerly, Greening } \\
\text { Greenpoint) \& Laundi } \\
\text { Keepseagle, Cherie Thunder } \\
\text { (Menikanaehkem, Inc), Joseph } \\
\text { Waukechon (College of }\end{array}$ & $\begin{array}{l}\text { Bushwick Inlet Park } \\
\text { Greenpoint, Brooklyn }\end{array}$ & $\begin{array}{l}\text { Local ecological knowledge } \\
\text { and Indigenous knowledge in } \\
\text { urban and community } \\
\text { forestry }\end{array}$ & $\begin{array}{l}\underline{\mathrm{http}: / / \text { gcefund.org/funded-projects/ }} \\
\text { greening-greenpoint/; } \\
\underline{\text { https://www.esf.edu/nativepeoples/projects. }} \\
\underline{\mathrm{htm}}\end{array}$ \\
\hline
\end{tabular}

Flick (University of Minnesota) Terri Carta (formerly Central Park Conservancy) \& Stephanie Freeman (USDA FS)

September 2017 Aminta Kilawan-Narine \& Rohan Narine (Sadhana)

Federal Building, Lower Manhattan

October $2017 \quad$ Kekuhi, Leila Dudley (Hālau 'Ōhi'a), \& Heather McMillen, Christian Giardina, Kainana Francisco Campbell, Svendsen, (USDA FS)

November 2017 Bibi Calderaro (Artist, educator, Battery Park, researcher. Science and Resilience Manhattan Institute at Jamaica Bay Fellow and Graduate Center, CUNY)

December 2017 Michelle Johnson (USDA FS)

January 2018

John Schellhas (USDA FS)

February 2018

Mirele Goldsmith (Independent evaluator affiliated with Hazon) \& Laura Landau (NYC Urban Field Station)

March 2018

Philip Silva (Environmental

Federal Building, researcher-practitioner, The New School)

April 2018

Luke Craven (University of New South Wales)

Federal Building, Lower Manhattan

May 2018

Annie Lederberg \& Tanasia Swift Hudson River (Billion Oyster Project)

Foundation Office, Lower Manhattan

June 2018
Federal Building,

Lower Manhattan Federal Building,

Lower Manhattan
Christina Perdos \& Maria Amin (NYC Parks Stewardship Team)
Place histories of Central Park, walking footprint of displaced community Seneca Village; discussed African American place histories by reading Trace

Hindu ritual practices on the https://www.sadhana.org/ waterfront, progressive Hinduism, and coastal stewardship in Jamaica Bay

Learning from Place

Workshop (see text)

Walking, embodiment, mindfulness, and connection to place

Cosmopolitan, nomadic lifestyles and sense of place African American Great

Migration and connection to Southern landscapes, including heirs' property in the Carolinas and urban farming and gardening in New York City

Makom Hadash office, Tu B'Shevat seder (Jewish birthday for trees, celebrated through food, song, and conversation) and discussion of Jewish environmentalism

Stewardship practices as knowledge work, uncovering our own every day knowledge creation practices as stewards of stewardship Stewardship system modeling of critical pathways and barriers using fuzzy cognitive modeling Paerdegat Basin, Brooklyn waterway restoration and education case study, in response to historic images of place guiding a photoelicitation exercise Participating in hands-on forest stewardship and invasive plant removal https://www.centralparknyc.org/ attractions/seneca-village-site; https://www.nyhistory.org/seneca/; http://www.lauretsavoy.com/books/trace/

http://www.thenatureofcities. com/2016/10/12/making-connections-andfeeding-relationships-reflections-from-abiocultural-axiom-of-aloha/

https://bibicalderaro.com/home.html; https://www.holesinthewallcollective.org/

https://www.nrs.fs.fed.us/nyc/

https://www.srs.fs.usda.gov/pubs/gtr/

gtr srs220.pdf

ttps://www.huffpost.com/entry/tu-bshvat-

an-ancient-holi b 810325? guccounter=1; http://hazon.org/wp-content/

uploads/2011/06/LeadersGuide.pdf;

https://wisephilanthropy.com/about-us/ mirele-b-goldsmith/

https://philipsilva.com/

https://www.lukecraven.com

https://www.systemeffects.com/\#/

https://billionoysterproject.org/

https://www.nycgovparks.org/reg/ stewardship 
sacred" spaces remain rare in workspace settings to our knowledge. We also found that the salons were particularly important for young professionals who shared that when they were able to step outside of organizational hierarchies, their contributions, impressions, and reflections were heard and so could be more easily understood and valued by other participants. Salon participants expressed how there was little time in the workday or workplace for personal reflection, validation of work, and critical thinking about the meaning of their work. It was clear that finding both time and a community of peers to explore ideas and reflect, personally and communally, was very important to the group. Here are quotes from four participants on benefits they realized from participating in the salons:

\begin{abstract}
It was amazing to have a few moments to dive into the worlds of other people who have a historical, cultural or professional relationship with landscape. This exposure is and will continue to be incredibly valuable to my process. What I really gained was the reminder of how rich these worlds are and how informative they can be to an artistic process.
\end{abstract}

I like [how] they often center around why we do the work that we do and how we can do it better. I don't get many opportunities to do this type of reflection, and I like that it's a good balance of structured and unstructured conversations.

Sense of community with other stewardship practitioners. Getting to know colleagues in the "stewardship" space -- those working specifically to engage people in care of place. Also, by way of formal and informal sharing I gained new perspectives and practices for my own stewardship work.

1) Inspiration to do this work when all other sources of inspiration run dry; 2) An opportunity to share my research in critical dialogue with peers; 3) Some new ways of thinking about research and action.

We sourced new topics and presenters from the group and through our networks, and through an iterative approach, sought to improve and refine each subsequent salon. We noticed that participants began to embrace relying on multiple narratives including personal stories, professional practices, and universal themes in this work. A set of regular attendees has expressed a desire to continue the Stewardship Salons, highlighting gratitude for the space to reflect and share in ways not possible in their respective professional settings. Going forward, we intend to collectively strengthen a community of practice that represents the unique aspects of stewardship in NYC, with those participants interested in and able to continue to meet. After a pause to reflect on what we learned from the first year, the Stewardship Salons resumed in February 2019. We redoubled our commitment to include the creation of a kuahu as a component of each salon and to be sure to share food as part of our standing ritual. Our new structure includes the planning team (LC and ES) setting the agenda and topics for salons that occur every other month, and leaving space for emergent topics, speakers, and ideas in the months between. This allows for the group to truly function as a rotating community of teachers and learners, rather than only one set of leaders playing a facilitating and curating role. Topics this second year included a walking tour and discussion of public art on the High Line Park in Manhattan, a feral landscape walk on Governor's Island, and a reading from a climate change novel. Stewardship Salons continue to occur both indoors, in office settings, but also include walks, bike rides, and other experiential engagements with place. From this ongoing work, we hope to identify and practice new ways of understanding place and to connect in new ways with place by engaging with culturally diverse communities and multiple ways of knowing. And we hope that our small group of colearners can be metaphorical ripples in a pond, sharing knowledge, practices, and rituals in their own personal lives, organizational settings, and beyond.

\section{DISCUSSION AND CONCLUSION}

As we reflect on the colearning that resulted from these exchanges, we revisit the $K i$ i $i$ framework and we use it here as an organizing principle for lessons learned and potential outcomes from our Learning from Place workshop. This framework resonates widely and can be found in stories and practices across many cultures. As illustrated in the quotes above, participants described the $\mathrm{Ki}^{i} i$ framework as scaffolding that offers a common language and grounding for discussions. Our reflections are organized by the three levels: personal, communal, and global.

\section{Ki i 'Iaka (personal, reflexive images)}

For some, there was initial uncertainty, even some skepticism regarding how personal self-reflection could enhance our work as researchers, managers, and policy makers. This concern, perhaps discomfort, quickly dissipated as stories emerged in group conversations, stories that often harkened back to our personal relationships with place, family, and friends. Sharing personal stories and insights, especially through a performative means, e.g., acting out stories or reciting original poetry, created vulnerability among participants. This helped to shift the way that people typically engage in professional settings and encouraged innovative ways of thinking and seeing in terms of stewardship and human-nature-place relationships. We heard of connections to city parks and suburban ponds, lakes, and rivers, geologic features, and open sky. We spoke of how this part of ourselves, our personal experience with and relationship to place, is not always considered part of the professionalized field of natural resource management. We discussed the importance of bringing Indigenous and local ecological knowledge frameworks into the urban setting with thoughtful intention and purposeful reflection. In the process we uncover a rich knowledge that emerges from place, culture, and practice. We discussed and even strategized how we might weave together our experiences, relying on multiple knowledge systems and ontologies, and integrate them into our stewardship efforts.

\section{Ki i i Honua (regional, communal images)}

As our group shifted the focus of our discussions into this next scale, we reflected on the themes and images we read about in the ka'ao from Inuit, Celtic, Chinese, and Aztec cultures. We also reflected on our own collaboratively developed ka $a o$, inspired by Bushwick Inlet Park, with these placed-based stories featuring former industrial sites, new condominium towers, the East River, quaking aspen trees, and translucent eels. Participants in this process had a strong interest in communicating regional scale meaning of these stories through multiple modes including narrated prose, song and dance, metaphors and memes, and artistic depiction of images on paper. 
We agreed that the ways federal, state, and local agencies often engage the public and each other, i.e., through scientific presentations or public comment sessions, are necessary for communicating with place-based stewards but are insufficient for fostering a broader stewardship ethic. We explored the limitations of approaches to engaging stewards and other practitioners that rely only on numbers, charts, and diagrams, because these do not engage the full range of emotions and senses operating during a presentation, and often do not capture how most people express their connections to each other and to place. As we worked to uncover and create a story common to the urban stewardship experiences of the participants, we identified the need to reflect on the myriad ways that resource managers have been portrayed in relationship to nature, from disruptive and exploitive conquers of nature to vigilant protectors of the Earth's ecosystems. We also explored how these apparently contrasting paradigms for resource management could be part of a more integrated placedbased model of stewardship where resources are sustained by the practitioner, while the practitioner is sustained by the resource. In this way, our group was able to imagine possibilities beyond our specific institutional missions and legacies to identify areas of common ground, as well as collective action.

\section{Ki'i Ākea (global, unifying images)}

As our group moved into identifying and interpreting universal themes in the stories, such as birth, death, sacrifice, and journeys of transformation, we returned to the idea of care for the land and for the people. We acknowledged that stewardship as commodity management or resource conservation for purely people's or nature's benefit was incomplete and too limiting for cultivating stewardship practices we desired for our places. And so, we engaged a vision of stewardship focused on perpetuating relationships among people and place (Kealiikanakaoleohaililani and Giardina 2016, Kealiikanakaoleohaililani et al. 2018, 2019), as well as the values that are fostered for the betterment of people and place (e.g., Chan et al. 2016a).

We discussed the importance of recognizing connections to places that are distant in terms of time and space, with the goal of including them in our concepts and practices of stewardship (Folke et al. 2016). Chan et al. (2016a:1465) suggest that by "cultivating relationships with organizations, and culturally sensitive relationships with faraway places, nongovernmental organizations might jumpstart a movement that takes real responsibility for the roles we play as complicit actors in marketdriven environmental impacts." The idea of connections among places, near and far, resonated with participants' sense of what it means to be "from New York City," as so many in the group shared their own stories from other places, including distant rural homelands, and how these stories had become intricately woven into their lives as residents of NYC's dense and intense metropolis.

During our discussions, participants shared the view that the rights and responsibilities stewards hold for their places stem from an investment in caring for an array of relationships to place including tangible, e.g., plant life, wildlife, buildings, and people, as well as intangible elements, e.g., histories, legends, and personal accounts, that give life to landscapes and seascapes as socialecological systems. Participants agreed that in the best case, these relationships among people and place are founded on reciprocal exchanges, and this reciprocity fosters and sustains a more holistic stewardship. Engaging in the type of stewardship that manifests from cultivating relationships that promote human and ecological well-being, enhance dialogue, and foster social trust often requires multiple ways of knowing. And so, expanding our capacity to know the world around us and to be intentional in our relationships with that world became the central tenets of this exchange. We concluded that these two tenets allow urban stewards to improve the biophysical features of a place, e.g., metrics of environmental quality such as clean water or percent green space, but also support the health and well-being of residents in these places, including physical, emotional, psychological, and spiritual dimensions. Although conventional, agency-based stewardship is effective at caring for biophysical resources, we all acknowledged that as practitioners, we are still learning how to practice stewardship such that our work sustains and where needed fosters the reciprocal relationships connecting people and place. We concluded that transboundary cultivation of these relationships is essential for the adoption and sustaining of equitable solutions to our most pressing environmental issues.

\section{Reflections on developing biocultural urban stewardship communities of practice}

We share our experiences to inspire others to start their own biocultural community of practice in an urban setting, and offer a few final reflections. (1) We easily acknowledge that the experiences we described here would not have been possible without Kekuhi Kealiikanakaoleohaililani. As a visionary, a master facilitator, and teacher, and the creator of Hālau 'Ōhi'a, she was able to elicit an openness and vulnerability from the Learning from Place participants that might be difficult to replicate in less skilled hands. If a dynamic and skilled master teacher is not immediately available to you, there are ways of adapting. For example, after working with Kumu Kekuhi to establish a framework and grounding, the co-organizers of the Stewardship Salons have adopted a method for leading where participants take turns. (2) Although we deeply support incorporating multiple ways of knowing and diverse cultural perspectives into this work, we recommend starting your community of practice by being grounded in one epistemological approach (as was done with the Learning from Place workshop) rather than drawing on multiple epistemologies from the beginning. Kumu Kekuhi's strong grounding in Hawaiian epistemology enabled a common language and framework that provided scaffolding for participants. Once they became familiar with this grounding, they were able to localize the framework for their own geographic, cultural, and occupational settings. The Hālau 'Ōhi'a tools and approaches drove the subsequent efforts with the Stewardship Salons that evolved to draw on multiple epistemologies. (3) We made the most of the time we had for the workshop, but as the name "Learning from Place" suggests, it would have deepened our experience to be able to spend more time in the place and be able to practice "listening" more to the places themselves. In addition, being exposed to the stories of multigenerational stewards of the land where we gathered would have also deepened our knowing from those places. This is a common practice followed by Hālau 'Ōhi'a when we visit other places and one we recommend for others. 


\section{Way forward: biocultural stewardship in the urban crucible} Research on the ecology of cities (Pickett et al. 2016, Burch et al. 2017) illuminates the social-ecological nature of built and natural environments within urban areas and people's connections to these environments. Going further, the concept of an ecology for cities (Childers et al. 2015, Grove et al. 2015, Pickett et al. 2016) promotes a normative perspective that our policies, plans, programs, and practices can be used to seek and then steer urban systems toward a more just, sustainable, and equitable condition. We see the colearning engagements that we created as one approach to advancing an ecology for cities where awareness for and appreciation of biocultural stewardship is prioritized. An urban social-ecological approach orients us toward meanings of biocultural stewardship that incorporate the conservation of biodiversity, but also safeguards the supply of resources for city dwellers and their access to nature, while promoting sustainability objectives of reduced impact on the urban environment (Andersson et al. 2014). Creative, transformative approaches are being taken globally to understand stewardship in urban areas as a means to account for and appreciate diversity (Fisher et al. 2015, Grove et al. 2015, Buizer et al. 2016, Kealiikanakaoleohaililani and Giardina 2016, Muñoz-Erickson et al. 2017, Svendsen et al. 2016b; Campbell et al. in press) yet efforts to synthesize across these lessons about stewardship are relatively novel, and the means for productive interaction among researchers, resource stewards, and policy entities are lacking (McMillen et al. 2016). Through this effort, we suggest that next steps include broadening our understanding of stewardship and advancing an enhanced vision of stewardship that recognizes connection to place and ancestral wisdom that is passed down through generations. Densely populated, multicultural urban environments may appear to be unlikely starting places for these discussions on applying Indigenous and place-based ways of knowing and engaging with natural resources; however, the intense layering of experiences and practices in a bounded space might just be the urban crucible that can create new systems of stewardship that promote biophysical and sociocultural resilience into the future.

Responses to this article can be read online at: http://www.ecologyandsociety.org/issues/responses. php/11386

\footnotetext{
Acknowledgments:

Funding for the Learning from Place workshop in NYC was funded by the USDA Forest Service, in part by the Pacific Southwest Research Station and in part by the Northern Research Station. We thank Cynthia McArthur for thoughtfully commenting on the paper. We thank Melanie Leilā Dudley for her support with Hālau 'Ōhi'a content for the Learning from Place workshop in NYC. We thank Michelle Johnson, Laura Landau, Renae Reynolds, David Maddox, the New York City Department of Parks and Recreation, and all Learning from Place and Stewardship Salon participants for their involvement in the cocreation of knowledge at our workshop and salons. We thank Hālau 'Ōhi'a for opening its doors in Hilo for a two-day site visit by Lindsay Campbell. All photographs were taken by Giles Ashford and used with permission. The findings and conclusions in this publication are those of the authors and should
}

not be construed to represent any official USDA or U.S. Government determination or policy.

\section{LITERATURE CITED}

Agyeman, J., and B. Angus. 2003. The role of civic environmentalism in the pursuit of sustainable communities. Journal of Environmental Planning and Management 46 (3):345-363. https://doi.org/10.1080/0964056032000096901

Andersson, E., S. Barthel, S. Borgström, J. Colding, T. Elmqvist, C. Folke, and Å. Gren. 2014. Reconnecting cities to the biosphere: stewardship of green infrastructure and urban ecosystem services. Ambio 43(4):445-453. https://doi.org/10.1007/s13280-014-0506y

Barthel, S., J. Colding, T. Elmqvist, and C. Folke. 2005. History and local management of a biodiversity-rich, urban cultural landscape. Ecology and Society 10(2):10. https://doi.org/10.5751/ ES-01568-100210

Bennett, N. J., T. S. Whitty, E. Finkbeiner, J. Pittman, H. Bassett, S. Gelcich, and E. H. Allison. 2018. Environmental stewardship: a conceptual review and analytical framework. Environmental Management 61(4):597-614. https://doi.org/10.1007/s00267-017-0993-2

Berkes, F. 2012. Sacred ecology: traditional ecological knowledge and resource management. Third edition. Routledge, New York, New York, USA.

Berkes, F., C. Folke, and J. Colding, editors. 1998. Linking social and ecological systems. University of Cambridge, Cambridge, UK.

Blanc, N., and F. Paddeu. 2018. L'environnementalisme ordinaire. Transformer l'espace public métropolitain à bas bruit? EspacesTemps.net, 5 April. [online] URL: https://www. espacestemps.net/en/articles/lenvironnementalisme-ordinaire-transformerlespace-public-metropolitain-a-bas-bruit/,

Brulle, R. J. 2000. Agency, democracy, and nature: the U.S. environmental movement from a critical theory perspective. MIT Press, Cambridge, Massachusetts, USA. https://doi.org/10.7551/ mitpress/1158.001.0001

Buizer, M., B. Elands, and K. Vierikko. 2016. Governing cities reflexively: the biocultural diversity concept as an alternative to ecosystem services. Environmental Science and Policy 62:7-13. https://doi.org/10.1016/j.envsci.2016.03.003

Bullard, R. D. 1990. Dumping in Dixie: race, class, and environmental quality. Westview, Boulder, Colorado, USA.

Burch, W. R., Jr., and M. J. Grove. 1993. People, trees and participation on the urban frontier. Unasylva 44(173):19-27.

Burch, W. R., G. E. Machlis, and J. E. Force. 2017. The structure and dynamics of human ecosystems: toward a model for understanding and action. Yale University Press, New Haven, Connecticut, USA. https://doi.org/10.12987/yale/9780300137033.001.0001

Campbell, L. K., L. Landau, E. S. Svendsen, and M. Johnson. In press. Civic stewardship of urban ecosystems: forms of community engagement with landscapes and places. Environmental Issues Reader. Cognella Academic, San Diego, California, USA. 
Caston, D. 2013. Biocultural stewardship: a framework for engaging Indigenous cultures. Minding Nature 6(3):22-32.

Chan, J., L. Pennisi, and C. A. Francis. 2016b. Social-ecological refuges: reconnecting in community gardens in Lincoln, Nebraska. Journal of Ethnobiology 36(4):842-860. https://doi. org/10.2993/0278-0771-36.4.842

Chan, K. M. A., P. Balvanera, K. Benessaiah, M. Chapman, S. Díaz, E. Gómez-Baggethun, R. Gould, N. Hannahs, K. Jax, S. Klain, et al. 2016a. Why protect nature? Rethinking values and the environment. Proceedings of the National Academy of Sciences 113(6):1462-1465. https://doi.org/10.1073/pnas.1525002113

Chan, K. M. A., R. K. Gould, and U. Pascual. 2018. Editorial overview: Relational values: what are they, and what's the fuss about? Current Opinion in Environmental Sustainability 35:A1A7. https://doi.org/10.1016/j.cosust.2018.11.003

Chapin III, F. S., S. R. Carpenter, G. P. Koflnas, C. Folke, N. Abel, W. C. Clark, P. Olsson, D. M. S. Smith, B. Walker, O. R. Young, F. Berkes, R. Biggs, J. M. Grove, R. L. Naylor, E. Pinkerton, W. Steffen, and F. J. Swanson. 2009. Ecosystem stewardship: sustainability strategies for a rapidly changing planet. Trends in Ecology and Evolution 25(4):241-249. https://doi.org/10.1016/j. tree.2009.10.008

Childers, D. L., M. L. Cadenasso, J. M. Grove, V. Marshall, B. McGrath, and S. T. A. Pickett. 2015. An ecology for cities: a transformational nexus of design and ecology to advance climate change resilience and urban sustainability. Sustainability 7 (4):3774-3791. https://doi.org/10.3390/su7043774

Cocks, M., J. Alexander, L. Mogano, and S. Vetter. 2016. Ways of belonging: meanings of "nature" among Xhosa-speaking township residents in South Africa. Journal of Ethnobiology 36 (4):820-841. https://doi.org/10.2993/0278-0771-36.4.820

Cocks, M., and T. Dold. 2006. Cultural significance of biodiversity: the role of medicinal plants in urban African cultural practices in the Eastern Cape, South Africa. Journal of Ethnobiology 26(1):60-81. $\underline{\text { https://doi.org/10.2993/0278-0771 }}$ (2006)26[60:CSOBTR]2.0.CO;2

Cocks, M. L., and F. Wiersum. 2014. Reappraising the concept of biocultural diversity: a perspective from South Africa. Human Ecology 42:727-737. https://doi.org/10.1007/s10745-014-9681-5

Colding, J., J. Lundberg, and C. Folke. 2006. Incorporating greenarea user groups in urban ecosystem management. Ambio 35:237-244. https://doi.org/10.1579/05-A-098R.1

Connolly, J. J. T., E. S. Svendsen, D. R. Fisher, and L. K. Campbell. 2013. Organizing urban ecosystem services through environmental stewardship governance in New York City. Landscape and Urban Planning 109:76-84. https://doi.org/10.1016/j.landurbplan.2012.07.001

Connolly, J. J. T., E. S. Svendsen, D. R. Fisher, and L. K. Campbell. 2014. Networked governance and the management of ecosystem services: the case of urban environmental stewardship in New York City. Ecosystem Services 10:187-194. https://doi. org/10.1016/j.ecoser.2014.08.005

Dacks, R., T. Ticktin, A. Mawyer, S. Caillon, J. Claudet, P. Fabre, S. D. Jupiter, J. McCarter, M. Mejia, P. Pascua, E. Sterling, and S. Wongbusarakum. 2019. Developing biocultural indicators for resource management. Conservation Science and Practice 1(6): e38. https://doi.org/10.1111/csp2.38

Dalton, S. E. 2001. The Gwynns Falls watershed: a case study of public and non-profit sector behavior in natural resource management. Dissertation. Johns Hopkins University, Baltimore, Maryland, USA.

Dockry, M. J., K. Hall, W. van Lopik, and C. M. Caldwell. 2016. Sustainable development education, practice, and research: an indigenous model of sustainable development at the College of Menominee Nation, Keshena, WI, USA. Sustainability Science 11:127-138. https://doi.org/10.1007/s11625-015-0304-X

Donatuto, J., E. E. Grossman, J. Konovsky, S. Grossman, and L. W. Campbell. 2014. Indigenous community health and climate change: integrating biophysical and social science indicators. Coastal Management 42(4):355-373. https://doi.org/10.1080/08920753.2014.923140

Elands, B. H. M., K. Vierikko, E. Andersson, L. K. Fischer, P. Gonçalves, D. Haase, I. Kowarik, A. C. Luz, J. Niemelä, M. Santos-Reis, and K. F. Wiersum. 2019. Biocultural diversity: a novel concept to assess human-nature interrelations, nature conservation and stewardship in cities. Urban Forestry \& Urban Greening 40:29-34. https://doi.org/10.1016/j.ufug.2018.04.006

Elands, B. H. M., K. F., Wiersum, A. E. Buijs, and K. Vierikko. 2015. Policy interpretations and manifestation of biocultural diversity in urbanized Europe: conservation of lived biodiversity. Biodiversity and Conservation 24:3347-3366. https://doi. org/10.1007/s10531-015-0985-6

Enqvist, J. 2017. Stewardship in an urban world civic engagement and human - nature relations in the Anthropocene. Dissertation. Stockholm University, Stockholm, Sweden.

Enqvist, J. P., L. K. Campbell, R. C. Stedman, and E. S. Svendsen. 2019. Place meanings on the urban waterfront: a typology of stewardships. Sustainability Science 14:589-605. https://doi. org/10.1007/s11625-019-00660-5

Fernández-Llamazares, Á., and M. Cabeza. 2018. Rediscovering the potential of Indigenous storytelling for conservation practice. Conservation Letters 11(3):e12398. https://doi.org/10.1111/ conl.12398

Fisher, D. R., L. K. Campbell, and E. S. Svendsen. 2012. The organisational structure of urban environmental stewardship. Environmental Politics 21(1):26-48. https://doi.org/10.1080/0964$\underline{4016.2011 .643367}$

Fisher, D. R., E. S. Svendsen, and J. Connolly. 2015. Urban environmental stewardship and civic engagement: how planting trees strengthens the roots of democracy. Explorations in Environmental Studies Series. Routledge, London, UK. https:// doi.org/10.4324/9781315857589

Folke, C., R. Biggs, A. V. Norström, B. Reyers, and J. Rockström. 2016. Social-ecological resilience and biosphere-based sustainability science. Ecology and Society 21(3):41. https://doi.org/10.5751/ ES-08748-210341

Gavin, M. C., J. McCarter, A. Mead, F. Berkes, J. R. Stepp, D. Peterson, and R. Tang. 2015. Defining biocultural approaches to conservation. Trends in Ecology and Evolution 30(3):140-145. https://doi.org/10.1016/j.tree.2014.12.005 
Gillison, G. 1980. Images of nature in Gimi Thought. Pages 143-173 in M. Strathern and C. MacCormack, editors. Nature, culture and gender. Cambridge University Press, Cambridge, UK.

Grove, J. M., M. Cadenasso, S. Pickett, and G. Machlis. 2015. The Baltimore school of urban ecology: space, scale, and time for the study of cities. Yale University Press, New Haven, Connecticut, USA. https://doi.org/10.12987/yale/9780300101133.001.0001

Johnson, J. T. 2013. Kaitiakitanga: telling the stories of environmental guardianship. Pages 127-138 in J. T. Johnson and S. C. Larsen, editors. A deeper sense of place. Oregon State University Press, Corvallis, Oregon, USA.

Johnson, J. T., R. Howitt, G. Cajete, F. Berkes, R. P. Louis, and A. Kliskey. 2016. Weaving Indigenous and sustainability sciences to diversify our methods. Sustainability Science 11:1-11. https:// doi.org/10.1007/s11625-015-0349-X

Kealiikanakaoleohaililani, K., and C. P. Giardina. 2016. Embracing the sacred: an Indigenous framework for tomorrow's sustainability science. Sustainability Science 11:57-67. https://doi. org/10.1007/s11625-015-0343-3

Kealiikanakaoleohaililani, K., N. Kurashima, K. S. Francisco, C. P. Giardina, R. P. Louis, H. McMillen, C. K. Asing, K. Asing, T. A. Block, M. Browning, K. Camara, L. Camara, M. L. Dudley, M. Frazier, N. Gomes, A. E. Gordon, M. Gordon, L. Heu, A. Irvine, N. Kaawa, S. Kirkpatrick, E. Leucht, C. H. Perry, J. Replogle, L.-L. Salbosa, A. Sato, L. Schubert, A. Sterling, A. L. Uowolo, J. Uowolo, B. Walker, A. N. Whitehead, and D. Yogi. 2018. Ritual + sustainability science? A portal into the science of Aloha. Sustainability 10(10):3478. https://doi.org/10.3390/ $\underline{\mathrm{su} 10103478}$

Kealiikanakaoleohaililani, K., H. McMillen, C. Giardina, and K. Francisco. 2019. Cultivating sacred kinship to strengthen resilience. Pages 188-207 in L. K. Campbell, E. S. Svendsen, N. F. Sonti, S. Hines, and D. Maddox, editors. Green readiness, response, and recovery: a collaborative synthesis. General Technical Report NRS-P-185. U.S. Forest Service, Newtown Square, Pennsylvania, USA. https://doi.org/10.2737/NRS-GTRP-185-paper13

Krasny, M., and K. Tidball. 2015. Civic ecology: adaptation and transformation from the ground up. MIT Press, Cambridge, Massachusetts, USA. https://doi.org/10.7551/mitpress/9780262$\underline{028653.001 .0001}$

Manning, P. 2013. Migration in world history. Second edition. Routledge, New York, New York, USA. https://doi. org/10.4324/9780203100707

McGregor, D. 2007. Nā Kua āina: living Hawaiian culture. UH Press, Honolulu, Hawai'i, USA.

McMillen, H., L. K. Campbell, E. S. Svendsen, and R. Reynolds. 2016. Recognizing stewardship practices as indicators of social resilience: in living memorials and in a community garden. Sustainability 8(8):775. https://doi.org/10.3390/su8080775

McMillen, H., T. Ticktin, and H. K. Springer. 2017. The future is behind us: traditional ecological knowledge and resilience over time on Hawai'i Island. Regional Environmental Change 17:579-592. https://doi.org/10.1007/s10113-016-1032-1
Merçon, J., S. Vetter, M. Tengö, M. Cocks, P. Balvanera, J. A. Rosell, and B. Ayala-Orozco. 2019. From local landscapes to international policy: contributions of the biocultural paradigm to global sustainability. Global Sustainability 2:e7. https://doi. org/10.1017/sus.2019.4

Mertig, A. G., R. E. Dunlap, and D. E. Morrison. 2001. The environmental movement in the United States. Pages 448-481 in R. E. Dunlap and W. Michelson, editors. Handbook of environmental sociology. Greenwood, Westport, Connecticut, USA.

Morishige, K., P. Andrade, P. Pascua, K. Steward, E. Cadiz, L. Kapono, and U. Chong. 2018. Nā Kilo 'Āina: visions of biocultural restoration through Indigenous relationships between people and place. Sustainability 10(10):3368. https://doi. org/10.3390/su10103368

Muhumuza, M., and K. Balkwill. 2013. Factors affecting the success of conserving biodiversity in national parks: a review of case studies from Africa. International Journal of Biodiversity. 2013:798101. https://doi.org/10.1155/2013/798101

Muñoz-Erickson, T. A., C. A. Miller, and T. R. Miller. 2017. How cities think: knowledge co-production for urban sustainability and resilience. Forests 8(6):203. https://doi.org/10.3390/f8060203

Nash. R. 2014. Wilderness and the American mind. Yale University Press, London, UK.

Nesheim, I., S. S. Dhillion, and K. A. Stølen. 2006. What happens to traditional knowledge and use of natural resources when people migrate? Human Ecology 34(1):99-131. https://doi. org/10.1007/s10745-005-9004-y

Olsson, P., C. Folke, and T. Hahn. 2004. Social-ecological transformation for ecosystem management: the development of adaptive co-management of a wetland landscape in southern Sweden. Ecology and Society 9(4):2. https://doi.org/10.5751/ ES-00683-090402

Pascua, P., H. McMillen, T. Ticktin, M. Vaughan, and K. B. Winter. 2017. Beyond services: a process and framework to incorporate cultural, genealogical, place-based, and indigenous relationships in ecosystem service assessments. Ecosystem Services 26:465-475. https://doi.org/10.1016/j.ecoser.2017.03.012

Pickett, S. T. A., M. L. Cadenasso, D. L. Childers, M. J. McDonnell, and W. Zhou. 2016. Evolution and future of urban ecological science: ecology in, of, and for the city. Ecosystem Health and Sustainability 2(7):e01229. https://doi.org/10.1002/ ehs 2.1229

Romolini, M., J. M. Grove, and D. H. Locke. 2013. Assessing and comparing relationships between urban environmental stewardship networks and land cover in Baltimore and Seattle. Landscape and Urban Planning 120:190-207. https://doi. org/10.1016/j.landurbplan.2013.08.008

Salmón, E. 2000. Kincentric ecology: indigenous perceptions of the human - nature relationship. Ecological Applications 10 (5):1327-1332. https://doi.org/10.1890/1051-0761(2000)010[1327: keipot]2.0.co:2

Shava, S., M. E. Krasny, and K. G. Tidball, and C. Zazu. 2010. Agricultural knowledge in urban and resettled communities: 
applications to social-ecological resilience and environmental education. Environmental Education Research 16(5-6):575-589. https://doi.org/10.1080/13504622.2010.505436

Shutkin, W. A. 2000. The land that could be: environmentalism and democracy in the twenty-first century. MIT Press, Cambridge, Massachusetts, USA. https://doi.org/10.7551/mitpress/4091.001.0001

Sirianni, C. 2006. Can a federal regulator become a civic enabler? Watersheds at the U.S. Environmental Protection Agency. National Civic Review 95(3):17-34. https://doi.org/10.1002/ $\underline{\text { ncr.146 }}$

Sonti, N. F., and E. S. Svendsen. 2018. Why garden? Personal and abiding motivations for community gardening in New York City. Society \& Natural Resources 31(10):1189-1205. https://doi. org/10.1080/08941920.2018.1484971

Sterling, E. J., C. Filardi, A. Toomey, A. Sigouin, E. Betley, N. Gazit, J. Newell, S. Albert, D. Alvira, N. Bergamini, M. Blair, D. Boseto, K. Burrows, N. Bynum, S. Caillon, J. E. Caselle, J. Claudet, G. Cullman, R. Dacks, P. B. Eyzaguirre, S. Gray, J. Herrera, P. Kenilorea, K. Kinney, N. Kurashima, S. Macey, C. Malone, S. Mauli, J. McCarter, H. McMillen, P. Pascua, P. Pikacha, A. L. Porzecanski, P. de Robert, M. Salpeteur, M. Sirikolo, M. H. Stege, K. Stege, T. Ticktin, R. Vave, A. Wali, P. West, K. B. Winter, and S. D. Jupiter. 2017. Biocultural approaches to well-being and sustainability indicators across scales. Nature Ecology and Evolution 1:1798-1806. https://doi.org/10.1038/s41559-017-0349-6

Svendsen, E. S., and L. K. Campbell. 2008. Urban ecological stewardship: understanding the structure, function and management. Urban Ecology 1(1):1-32.

Svendsen, E. S., L. K. Campbell, D. R. Fisher, J. T. Connolly, M. L. Johnson, N. F. Sonti, D. H. Locke, L. M. Westphal, C. LeBlanc Fisher, J. M. Grove, M. Romolini, D. J. Blahna, and K. L. Wolf. 2016b. Stewardship mapping and assessment project: a framework for understanding community-based environmental stewardship. General Technical Report 156. U.S. Forest Service, Northern Research Station, Newtown Square, Pennsylvania, USA. https:// doi.org/10.2737/NRS-GTR-156

Svendsen, E. S., L. K. Campbell, and H. L. McMillen. $2016 a$. Stories, shrines, and symbols: recognizing psycho-social-spiritual benefits of urban parks and natural areas. Journal of Ethnobiology 36(4):881-907. https://doi.org/10.2993/0278-0771-36.4.881

Tengö, M., E. Brondizio, T. Elmquist, P. Malmer, and M. Spierenburg. 2014. Connecting diverse knowledge systems for enhanced ecosystem governance: the multiple evidence base approach. Ambio 43:579-591. https://doi.org/10.1007/s13280-014-0501-3

Tipa, G., and L. Teirney. 2006. A cultural health index for streams and waterways: a tool for nationwide use. Ministry for the Environment, Wellington, New Zealand. [online] URL: $\underline{\text { https:// }}$ www.mfe.govt.nz/sites/default/files/cultural-health-index-for-streamsand-waterways-tech-report-apr06.pdf

Turner, N. J., M. B. Ignace, and R. Ignace. 2000. Traditional ecological knowledge and wisdom of Aboriginal peoples in British Columbia. Ecological Applications 10(5):1275-1287. https://doi.org/10.1890/1051-0761(2000)010[1275:TEKAWO]2.0. $\mathrm{CO} ; 2$
Watts, V. 2013. Indigenous place-thought and agency amongst humans and non humans (First Woman and Sky Woman go on a European world tour!). Decolonization: Indigeneity, Education \& Society 2(1):20-34.

West, P. 2005. Translation, value, and space: theorizing an ethnographic and engaged environmental anthropology. American Anthropologist 107(4):632-642. https://doi.org/10.1525/ aa.2005.107.4.632

Westphal, L. M. 1993. Why trees? Urban forestry volunteers values and motivations. Pages 19-23 in P. Gobster, editor. Managing urban and high-use recreation settings. U.S. Forest Service North Central Research Station, St. Paul, Minnesota, USA.

Whyte, K. P., J. P. Brewer II, and J. T. Johnson. 2016. Weaving Indigenous science, protocols and sustainability science. Sustainability Science 1(11):25-32. https://doi.org/10.1007/ s11625-015-0296-6

Winthrop, R. H. 2014. The strange case of cultural services: limits of the ecosystem services paradigm. Ecological Economics 108:208-214. https://doi.org/10.1016/j.ecolecon.2014.10.005

Yagatich, W., A. M. G. Robertson, and D. R. Fisher. 2018. How local environmental stewardship diversifies democracy. Local Environment 23(4):431-447. https://doi.org/10.1080/13549839.2018.1428187 